\title{
Men on the Move: A Randomized Controlled Feasibility Trial of a Scalable, Choice-Based, Physical Activity and Active Transportation Intervention for Older Men
}

\author{
Dawn C. Mackey, Alexander D. Perkins, Kaitlin Hong Tai, Joanie Sims-Gould, \\ and Heather A. McKay
}

\begin{abstract}
We conducted Men on the Move, a 12-week randomized controlled feasibility trial of a scalable, choice-based, physical activity (PA) and active transportation intervention. Participants were community-dwelling men aged 60 years and older ( $n=29$ intervention [INT] and $n=29$ waitlist control [CON]). Trained activity coaches delivered: (a) one-on-one participant consultations to develop personal action plans for PA and active transportation, (b) monthly group-based motivational meetings, (c) weekly telephone support, (d) complimentary recreation and transit passes, and (e) pedometers and diaries for self-monitoring. Men on the Move demonstrated high rates of recruitment, retention, and intervention adherence. INT chose a variety of group-based and individual PAs and destinations for their personal action plans. At 12 weeks, INT achieved more steps, moderate-vigorous PA, and energy expenditure than CON. INT was also more likely to take transit and meet national guideline levels of PA. At 24 weeks follow-up, INT benefits were sustained for moderate-vigorous PA and energy expenditure.
\end{abstract}

Keywords: active travel, health promotion, mobility, older adult

Physical activity promotes mobility and independence (Pahor et al., 2014), helps to prevent and manage a variety of chronic diseases (Lee et al., 2012), reduces the risk of falls and related injuries (Gillespie et al., 2012), and enhances physical, mental, and social health (Bauman, Merom, Bull, Buchner, \& Fiatarone Singh, 2016) of older adults. Despite the numerous and irrefutable health benefits attributed to PA, we are in the midst of a pandemic of physical inactivity (Das \& Horton, 2016). Currently, $>90 \%$ of older Canadians are physically inactive and do not achieve the national guideline of $\geq 150$ min of moderate-vigorous physical activity (MVPA) per week (Colley et al., 2011). Adherence to national physical activity guidelines is similarly low among older adults in the United States (Troiano et al., 2008) and United Kingdom (National Health Service, 2011). Globally, physical inactivity is the fourth leading risk factor for premature mortality (World Health Organization, 2009), and it exerts an enormous burden on health care systems (Ding et al., 2016; Lee et al., 2012). As the population ages, there is an urgent need to

(C) 2019 The Authors. Published by Human Kinetics, Inc. This is an Open Access article distributed under the terms of the Creative Commons Attribution-NonCommercial-NoDerivatives 4.0 International License, CC BY-NC-ND 4.0, which permits the copy and redistribution in any medium or format, provided it is not used for commercial purposes, no modifications are made, and appropriate credit is given. See http://creativecommons.org/licenses/by-nc-nd/4.0. This license does not cover any third-party material that may appear with permission in the article. For commercial use, permission should be requested from Human Kinetics, Inc., through the Copyright Clearance Center (http://www.copyright.com).

Mackey is with the Dept. of Biomedical Physiology and Kinesiology, Simon Fraser University, Burnaby, British Columbia, Canada. Mackey, Perkins, Hong Tai, SimsGould, and McKay are with the Centre for Hip Health and Mobility, University of British Columbia, Vancouver, British Columbia, Canada. Sims-Gould and McKay are also with the Dept. of Family Practice, University of British Columbia, Vancouver, British Columbia, Canada. Address author correspondence to Dawn C. Mackey atdmackey@sfu.ca. develop physical activity promotion programs for older adults (Tremblay et al., 2011) that are not only effective but also scalable, so that they have potential to improve population health.

Traditionally, it has proved particularly challenging to reach and engage older men in healthy lifestyle and disease prevention programs (Caperchione et al., 2017). Within men's health research, reports on effective health promoting programs for young to middleage men have emerged (Caperchione et al., 2017; Gough, 2013; Hatchell, Bassett-Gunter, Clarke, Kimura, \& Latimer-Cheung, 2013; Hunt et al., 2014). Men have unique barriers to, and facilitators of, physical activity. Physical activity preferences are situated within and shaped, in part, by sex, gender, masculinities, and age (Caperchione et al., 2017). As a result, physical activity promotion in older men is likely to be most effective and scalable when it addresses their unique needs, interests, values, and motivations. However, it remains that very little is known about how to effectively design and scale physical activity strategies for older men.

Among evidence-based physical activity promotion programs, choice-based approaches successfully improved physical activity of older adults when delivered by research teams (Stewart et al., 1997) and more importantly, by community organizations (Stewart et al., 2001, 2006). Choice-based, flexible models allow programs to be tailored to individual activity preferences, motivations, health status, physical abilities, and financial and social resources. These attributes form the central tenets of scalability (Milat, King, Bauman, \& Redman, 2013).

Active transportation involves substituting motorized modes of daily transportation (e.g., driving) with active modes of transportation (e.g., walking, cycling; van Heeswijck et al., 2015). There is compelling evidence that public transportation (e.g., riding the bus) is a form of active transportation, as it provides opportunities for physical activity, such as walking, before and after trips (Davis et al., 2011; Ding \& Gebel, 2012; Morency, Trepanier, \& Demers, 2011; Rissel, Curac, Greenaway, \& Bauman, 2012). Importantly, 
active transportation may be one of only a few practical options for older men to maintain their mobility when they stop driving (Kim, 2011). Previously, training on personal travel planning for older adults led to increased bus use (Stepaniuk, Tuokko, McGee, Garrett, $\&$ Benner, 2008). Thus, provision of transit passes and personal travel planning may be especially effective to encourage public transit use; however, this combination has not been evaluated previously.

Our primary aim was to assess feasibility of "Men on the Move" - a scalable, choice-based, physical activity and active transportation promotion model for older men. Our specific objectives were to (a) estimate rates of participant recruitment and retention, (b) estimate rates of intervention adherence, and (c) obtain initial estimates of intervention effect and variability on health outcomes of interest, including physical activity, active transportation, and mobility. Our findings will be used to guide design of future studies that seek to determine effectiveness and scalability of physical activity interventions for older adults.

\section{Methods}

\section{Trial Design and Setting}

Men on the Move was a parallel group, 1:1, randomized, controlled, single-blinded (outcome assessors), feasibility trial of a 12-week choice-based physical activity and active transportation model (ClinicalTrials.gov identifier: NCT02527655). The physical activity intervention components were similar to those used in the Community Healthy Model Program for Seniors (CHAMPS; Stewart et al., 1997). Men on the Move differed from CHAMPS by its focus on older men and by the addition of novel intervention components that were designed to promote active transportation, including transit training, personal travel planning, and provision of complimentary transit passes. Reporting of this trial followed CONSORT guidelines.

The trial had three primary data collection points: a baseline assessment (T0), a 12-week follow-up assessment at intervention end (T1), and a 24-week follow-up (T2). The study was conducted in Vancouver, BC, Canada. In 2016, Vancouver had a population of 631,500, and its metropolitan area has a population of 2.5 million (Statistics Canada, 2017). Of the 2.5 million residents in Metro Vancouver, $15.5 \%$, or 387,000 people, are 65 years and older. We partnered with four community centers in Vancouver who were trained to assist with intervention delivery. We targeted recruitment throughout the Metro Vancouver region with an emphasis on the City of Vancouver.

\section{Participants}

We determined eligibility by a standard telephone screening interview. Community-dwelling men were included if they were at least 60 years of age, wanted to be more physically active, had not participated in any strength training or aerobic exercise classes in the past 3 months, and did not have plans to be out of town for $\geq 7$ days during the study. Men who answered "Yes" to any follow-up question about a medical condition on the Physical Activity Readiness Questionnaire Plus (Warburton, Jamnik, Bredin, \& Gledhill, 2018) were required to obtain written permission to participate from a physician before enrolling; the study reimbursed for any associated costs. Following T0 assessments, men were randomly assigned to intervention (INT; 12-week choice-based physical activity and active transportation intervention) or waitlist control (CON; no intervention for first 12 weeks, then offered intervention), as described below.
The study was approved by the research ethics boards of the three participating institutions (Simon Fraser University, University of British Columbia, and Vancouver Coastal Health Research Institute). Eligible individuals received study information and the consent form through e-mail following screening and reviewed them in-person with the study coordinator at the T0 assessment. All participants provided written informed consent.

\section{Recruitment}

We recruited participants over 6 weeks in August and September, 2015. We placed advertisements in two community newspapers; sent recruitment e-mails to relevant groups (e.g., health professional associations, university alumni and retirement associations, and disease foundations); displayed posters in neighborhood associations, senior's centers, public libraries, community centers, and health care centers; and advertised the study by word-of-mouth through older adult certified fitness instructors.

\section{Measures}

Participants completed a 2-hr in-person T0 assessment between September 15 and October 2, 2015. T0 assessments included questionnaires, physical measurements, subjective (by questionnaire) and objective (by accelerometer) measures of physical activity, and self-report of active transportation (by travel diary). At intervention end, we completed 1.5-hr in-person $\mathrm{T} 1$ assessments (12-week follow-up) between January 8 and 18, 2016. As before, we administered questionnaires, took physical measurements, and assessed physical activity and active transportation. At 24 weeks (12 weeks after intervention end), we repeated the 1.5-hr in-person follow-up assessments (T2) between April 4 and 14, 2016 for CON and between April 18 and 25, 2016 for INT. Assessments were conducted at the partner community centers in Vancouver or our research center (Centre for Hip Health and Mobility), per participant preference. Participants received a \$20 honorarium at each assessment.

Descriptive measures. Demographic information was ascertained by questionnaire and included age, birthplace, ethnicity, marital status, living arrangement, education, employment status, household income, home ownership, duration lived in current residence and neighborhood, driver's license, and access to a car. Participants self-reported degree of difficulty walking one quarter of a mile outside on level ground or up 10 steps without resting; any difficulty on either task indicated mobility limitation (Visser et al., 2005). Participants also reported presence of and reasons for limitations in getting out and about in their neighborhood, whether they liked walking outside, confidence walking in their neighborhood, weekly physical activity, and whether they had fallen in the past 6 months. Medical history was assessed using the Functional Comorbidity Index (Groll, To, Bombardier, \& Wright, 2005). Fear of falling was assessed by the Falls Efficacy Scale (Yardley et al., 2005), and physical fatigability by the Pittsburgh Fatigability Scale (Glynn et al., 2015). Height (m) was measured using a mobile stadiometer (Seca 217; Seca North America, Chino, CA), and weight $(\mathrm{kg})$ was measured using a mobile digital scale (Seca Bella 840; Seca North America). Body mass index $\left(\mathrm{kg} / \mathrm{m}^{2}\right)$ was calculated.

Primary outcome: Feasibility. We set predetermined feasibility targets. Specifically, to achieve our primary goal of determining rates of participant recruitment, retention, and adherence to the intervention, we defined success for recruitment as enrolling 50\% of individuals screened. We defined success for retention in the trial as $80 \%$ of 
participants completing the final T2 assessment (Ashe et al., 2015), as it would not be feasible to plan, fund, and implement a large-scale trial if loss to follow-up over 24 weeks was greater than $20 \%$. We defined success for adherence to the intervention as $60 \%$ of participants attending each group-based motivational meeting and a one-on-one consultation, and at least six of 12 weekly telephone check-ins. This level is consistent with adherence to physical activity interventions in trials of older adults and recommendations from implementation science experts (Durlak \& DuPre, 2008; Pahor et al., 2014).

Secondary outcomes: Physical activity, active transportation, and mobility. We assessed physical activity behavior, active transportation behavior, and measures of mobility at T0, T1, and T2.

Physical activity: Physical activity was assessed objectively using ActiGraph GTX3+ (ActiGraph LLC, Pensacola, FL) triaxial accelerometers worn at the hip during waking hours for 7 consecutive days at each measurement time point (removing them only for sleep and before any contact with water). We collected the following outcomes from accelerometers: MVPA (min/day), moderate physical activity (min/day), light physical activity (LPA; min/day), sedentary behavior (min/day), and step count (steps/day). Sedentary behavior was normalized to total daily wear time (percentage of day). We reintegrated raw data (collected at $60 \mathrm{~Hz}$ ) to 60-s epochs. Data were excluded if they showed 90 min of continuous zeroes (interpreted as nonwear time). Each participant's accelerometry data had to include at least 3 days with at least $8 \mathrm{hr}$ of wear time on each day to be included in the analysis. Data from valid wear days were averaged so outcomes could be expressed per day. Based on previous research (Ashe et al., 2015; Freedson, Melanson, \& Sirard, 1998; Gorman et al., 2014), we used the following cut points to interpret intensity: $<99$ counts/min (cts/min) as sedentary time, 100 $1,951 \mathrm{cts} / \mathrm{min}$ as LPA, 1,952-5,724 cts/min as moderate physical activity, $\geq 5,725 \mathrm{cts} / \mathrm{min}$ as vigorous physical activity.

Physical activity was also assessed using the CHAMPS questionnaire, a valid and reliable self-report tool for older adults (Stewart et al., 1997). We assessed the following outcomes from the CHAMPS questionnaire: energy expenditure (kcal/week), number of all physical activities (\#/week), and number of MVPAs (\#/week).

Active transportation: Travel behavior was assessed using a self-report 7-day travel diary (Chudyk et al., 2015). Participants were asked to record all trips, where a trip was defined as one-way travel between two destinations. For each trip, participants were asked to record the mode of transportation. Data collected from travel diaries were deidentified and processed by a research assistant who was not aware of group assignments. From each travel diary, we calculated weekly number of walking trips, transit trips (where travel mode was recorded as transit or transit + walking), active trips (sum of trips where mode was recorded as walking, transit, biking, or some other active mode), car trips, and total trips. If a diary page was crossed out, or it was noted that no trips outside the home were taken for a particular day, the number of trips was set to 0 for that day. If a page was left blank, with or without the date entered, data were considered missing (Chudyk et al., 2015).

Mobility: We administered the Life-Space Assessment (Baker, Bodner, \& Allman, 2003) by interview to assess extent, frequency, and independence of movement in the past month across five levels (ranging from one's bedroom to outside one's town). We calculated the composite life-space score that ranged from 0 (restricted to one's bedroom) to 120 (daily travel outside one's town without assistance) by summing individual level scores (Mackey et al., 2016). We assessed lower extremity physical function with the short physical performance battery (SPPB), which included tests of gait speed, standing balance, and leg strength (Guralnik et al.,
1994; Pahor et al., 2014). Specifically, participants performed two usual-pace 6-m walk trials; time from the fastest trial was converted to gait speed $(\mathrm{m} / \mathrm{s})$. Standing balance was measured by recording the time (up to $10 \mathrm{~s}$ each) that each participant could hold side-byside, semitandem, and tandem stands. Leg strength was measured by recording time to complete five repeated chair stands with the instruction to stand up and sit down without using arms as fast as possible. Each test was scored from 0 to 4, and scores were summed to produce an overall SPPB score ranging from 0 to 12 . Finally, we assessed mean 6-m gait speed $(\mathrm{m} / \mathrm{s})$ from two repeated trials.

\section{Randomization}

Randomization was performed by the study coordinator using a web-based randomization tool (www.randomization.com). Eligible participants $(N=58)$ were assigned 1:1 to either the intervention (INT) or waitlist control (CON) group by random allocation. As this was a feasibility study, no stratification was used. Randomization was not performed until all T0 assessments were completed (including 7-day accelerometer and travel diary data collection) to ensure the measurement team was blinded to group assignments. The study coordinator informed all participants of their assignments.

\section{Blinding}

Group assignment was concealed to outcome assessors during T0, $\mathrm{T} 1$, and T2 assessments. Furthermore, only core members of the research team had access to participants' unique study identification codes, names, and group assignments.

\section{Intervention Group (INT)}

After T0 assessments, participants randomized to INT received a 12-week choice-based physical activity and active transportation intervention. The physical activity component was informed by CHAMPS (Stewart et al., 1997); the active transportation component was a novel addition. The intervention was delivered by activity coaches, certified fitness leaders who had specific training to work with older adults. Activity coaches completed approximately $12 \mathrm{hr}$ of centralized Men on the Move-specific training at our research center (Centre for Hip Health and Mobility). In brief, participants were offered and asked to participate in the following:

a. Group motivational meetings: Three monthly 60-min group motivational meetings led by an activity coach. These motivational meetings were designed to provide knowledge, the opportunity to engage in interactive activities with group members, a sense of belonging to a program, social interaction, and the possibility of meeting others with whom to be physically active. The first group motivational meeting was the kickoff event for the intervention and focused on the health benefits of physical activity including (a) the importance of physical activity to the health and functioning of older adults, (b) safe physical activity for older adults, (c) that physical activity need not be strenuous to be beneficial, and (d) that physical activity can be fun and provide social opportunities. The second group motivational meeting focused on active transportation, including (a) definitions, (b) benefits, (c) obstacles and solutions to active transportation, and (d) specific training on how to use mobile devices to access websites and applications to plan trips to destinations using different modes of active transportation. The third group motivation meeting focused on maintenance of regular 
physical activity, including (a) recognizing and overcoming personal obstacles, (b) short- and long-term benefits, and (c) planning to continue with physical activity.

b. One-on-one consultation: A single 60-min one-on-one consultation with their activity coach was provided for participants to develop a personal action plan for physical activity and a personal travel plan. At the beginning of the consultation, the activity coach reviewed the participant's current levels of physical activity and personal barriers and solutions to participating in physical activity, helped them identify short- and long-term physical activity goals, and helped them to complete their personal action plan for physical activity. This was intended to leverage existing community-based options for physical activity, as well as home-based endeavors, all of which were tailored to the participants' interests, resources, abilities, health, income, and transportation options to promote sustainability over the long-term. The personal action plan specified what, where, when, how, and with whom physical activities would take place. The activity coach encouraged participants to work toward undertaking physical activity three to five times per week in a progressive manner to minimize risk of injury. Activity coaches then inquired about current and past use of active modes of transportation including walking and public transit, as well as personal barriers and solutions to active transportation. Activity coaches also helped participants to complete their personal travel plan, which specified why, how (e.g., by walking, biking, or taking public transit), with whom, and when participants would travel to reach their chosen destinations of interest. Participants were encouraged to identify possible barriers to their travel plan and possible solutions to overcome those barriers. They were also encouraged to add new destinations to their personal travel plan after 6 weeks. Participants and activity coach jointly signing off on their personal physical activity and active travel plans.

c. Transit training: A single 60-min group transit training workshop was led by a community outreach staff member of the local transit authority, Translink. This session covered the basics of using transit, planning routes, and paying for trips.

d. Activity logs: Daily, participants were asked to record the type, intensity, location, and duration of each physical activity they participated in, as well with whom they completed the activity (alone, with a friend, and with a group), and the mode of transportation they used to get to and from the location of their activity. They were also asked to record their daily step counts from their pedometer.

e. Pedometer: For self-monitoring, participants received a pedometer (Omron HJ-112; Omron Corp, Kyoto-Shi, Japan) at their one-on-one consultation and were instructed to record their daily step count in their activity log.

f. Written physical activity resources: Participants received a participant manual containing a variety of written materials, including national physical activity guidelines for older adults, a table of rating of perceived exertion to help them understand different activity intensities, and a variety of handouts. The research team also distributed a newsletter during the intervention, which contained healthy living tips.

g. Weekly telephone support: Activity coaches conducted weekly 15-min telephone check-ins to explore the participant's health, well-being, and progress with their personal action plans for physical activity and travel. These provided an opportunity for participants to find solutions to obstacles that might otherwise limit success in accomplishing goals set out in their action plans.

h. Incentives: Participants received complimentary passes to a community fitness center of their choice or had the costs of selected courses covered. Activity coaches were available to help facilitate registration in community fitness center courses following one-on-one consultations. Participants were also provided with a complimentary transit pass for the duration of the intervention to encourage active transportation by use of public transit.

i. iPads: Participants received training on the basic operation of an iPad during their T0 assessment and took home an iPad Mini 2 (Apple Inc., Cupertino, CA) for use throughout the 12 -week intervention. An application prompted participants to enter their step count twice daily (morning and evening), and participants were encouraged to use the iPad Mini to support their active transportation pursuits.

Four partner community centers provided space for delivery of intervention components (e.g., group and one-on-one meetings) and offered a wide variety of physical activity programs for older adults, which participants could choose from. The intervention is described in TIDieR checklist format (Hoffmann et al., 2014) in Supplementary Table S1 (available online). The specific behavior change techniques used in each component of the intervention are listed according to the CALO-RE taxonomy (Michie et al., 2011) in Supplementary Table S2 (available online).

\section{Waitlist Control Group (CON)}

For the duration of the 12-week intervention, the CON group did not receive any information regarding the importance of physical activity or active transportation. At the end of 12 weeks, the intervention was offered to the control group. Like the INT group, the CON group received an iPad at their T0 assessment, but they were not prompted to record step counts or encouraged to use the iPad to support active transportation behavior. At the midpoint of the study (6 weeks), we held an iPad skills workshop for the CON group to maintain contact with participants and promote attendance at the T1 measurement sessions. This workshop covered how to download applications, browse the Internet, connect to $\mathrm{Wi}-\mathrm{Fi}$, and use e-mail. This workshop did not cover topics related to physical activity, active transportation, or healthy living.

\section{Adverse Events Monitoring}

We asked all study participants to report any adverse events or significant changes to their health to the study coordinator. In addition, we asked activity coaches to report any concerns about participant health to the study coordinator. At the one-on-one consultation, each participant and their activity coach reviewed the Physical Activity Readiness Questionnaire Plus that was originally completed during telephone screening. If a participant's health changed in a way that might influence their participation in physical activity, we asked them to obtain physician approval before continuing with their action plans.

\section{Sample Size Planning}

We aimed to recruit 60 participants (30 per group). A formal sample size calculation was not appropriate because the primary 
outcomes were concerned with feasibility, specifically recruitment, retention, and adherence (Arain, Campbell, Cooper, \& Lancaster, 2010). Rather, our sample size was justified by the following rationale. First, one objective of the study was to estimate intervention effects and variability on health outcomes, which would allow more informed sample size planning for a future large-scale randomized controlled trial. To estimate variability with adequate precision, Whitehead et al. (2016) recommended 25 participants per treatment arm for standardized effect sizes that are small (0.2). Based on our previous work, we also estimated $10 \%$ loss of participants over the 12-week intervention, so we aimed to recruit 30 participants per group. Second, we felt that 30 participants per group were large enough to inform us about the feasibility of recruitment, retention, and adherence.

\section{Statistical Analysis}

Data were summarized as mean $(S D)$ for normally distributed continuous variables, median (25\%tile-75\%tile) for skewed continuous variables, and $n(\%)$ for categorical variables. To estimate intervention effects (INT vs. CON) at $\mathrm{T} 1$ in normally distributed continuous physical activity outcome measures, we used linear regression models with the $\mathrm{T} 1$ value as the dependent variable, group as the independent variable, and the T0 value as a covariate; we reported mean differences with corresponding $95 \%$ confidence intervals (CIs). To estimate intervention effects in skewed continuous outcomes (vigorous physical activity and SPPB score), we used the Mann-Whitney-Wilcoxon test. To estimate intervention effects in the odds of dichotomous physical activity and active transportation outcome measures at $\mathrm{T} 1$, we used logistic regression with adjustment for T0 values; we reported odds ratios with 95\% CIs. To estimate intervention effects in the rates of count-based active transportation outcome measures (e.g., \# trips/week) at T1, we used negative binomial regression adjusting for T0 values; we reported rate ratios and corresponding 95\% CIs. Where a 95\% CI did not cross one sensitivity of the outcome to a difference in intervention arms was suggested.

To examine retention of intervention effects within the intervention group, we used paired samples $t$ tests to compare normally distributed continuous outcome measures at $\mathrm{T} 2$ versus $\mathrm{T} 1$ as well as T2 versus T0, the Mann-Whitney-Wilcoxon test to compare skewed continuous variables at $\mathrm{T} 2$ versus $\mathrm{T} 1$ and $\mathrm{T} 2$ versus $\mathrm{T} 0$, and a two-tailed Chi-square test to compare dichotomous physical activity and active transport outcomes at T2 versus $\mathrm{T} 1$ and $\mathrm{T} 2$ versus T0. We considered (a) presence of difference between T0 and $\mathrm{T} 2$ and/or (b) lack of difference between $\mathrm{T} 1$ and $\mathrm{T} 2$ as evidence of effect retention. All analyses were conducted using $\mathrm{R}$ software (R Foundation for Statistical Computing, Vienna, Austria).

\section{Results}

\section{Recruitment and Screening}

The Men on the Move Study was conducted August 2015 through May 2016 (includes recruitment and T2 assessments). In total, 94 individuals responded to study advertisements (Figure 1). Of these contacts, $60(64 \%)$ were by phone and $34(36 \%)$ were by e-mail. The most successful methods of recruitment were newspaper advertisements $(n=32,34 \%)$, e-mail advertisements $(n=22,23 \%)$, friend and family referral $(n=11,12 \%)$, and posters $(n=8,9 \%)$. Following telephone screening of these 94, 57 (62\%) individuals were eligible immediately; another $15(16 \%)$ were asked to obtain physician approval based on their responses to the Physical
Activity Readiness Questionnaire Plus, and eight obtained approval. Thus, 65 individuals met study eligibility criteria. Of these, 58 (62\% of 94 initial respondents) enrolled, provided informed consent, and completed a baseline assessment.

\section{Baseline Participants Characteristics}

At T0, participants were aged 71.9 (6.6) years (mean [SD]: age range $=61.0-87.6$ years), with body mass index of $27.7(4.8) \mathrm{kg} / \mathrm{m}^{2}$ (Table 1). Most were of European descent (62\%), with some university education or greater $(67 \%)$, and were currently retired or not working (76\%). Among the $50 \%$ born outside of Canada, average length of stay in Canada was 46.0 (9.6) years. Most men were married or living with a common law spouse (64\%), 31\% reported living alone. On average, men had lived in their current neighborhood for 23.3 (17.2) years, and most owned their residence $(60 \%)$, had a driver's license (97\%), and access to a vehicle $(91 \%)$. The most common reasons for feeling limited in getting out and about in one's neighborhood were health reasons $(16 \%)$ and personal finances (12\%); 35\% reported an annual household income $<\$ 25,000$, and $26 \%$ reported $\$ 25,000-\$ 49,999$. The majority $(76 \%)$ said that they somewhat or very much liked to walk outside, and $86 \%$ felt somewhat or very confident walking in their neighborhood.

Thirty-five percent of men reported that they did not achieve 30 min or more of physical activity on any day in the past week. Difficulty walking one quarter mile outside or walking up 10 steps without resting, indices of mobility limitation, were uncommon (16\% and $8 \%$, respectively). Men reported low levels of physical fatigability (17.7 [8.8] out of 50) and strong levels of falls efficacy (19.0 [17.0-23.8]) on a scale of 16-64, where higher scores indicate greater fear of falling. Of the chronic medical conditions we ascertained, the most prevalent were arthritis (26\%), diabetes $(16 \%)$, and anxiety/panic disorders (12\%).

\section{Randomization and Retention}

Following T0 assessments, 29 participants were randomized to each of INT and CON groups (Figure 1). At 12 weeks, 3/58 (5\%) participants were lost to follow-up, whereas 55/58 (95\%) participants completed the T1 assessment, including 27/29 (93\%) INT and 28/29 (97\%) CON participants. Of these 55, $44(80 \%)$ provided valid accelerometry data, and $48(87 \%)$ provided valid travel diary data. By 24 weeks, 7/58 (12\%) participants were lost to follow-up, whereas 51/58 (88\%) completed the T2 assessment, including $25 / 29(86 \%)$ intervention and 26/29 (90\%) control participants. Of these $51,43(84 \%)$ provided valid accelerometry data, and $47(92 \%)$ provided valid travel diary data.

\section{Intervention Adherence}

Among INT, 28 (97\%) attended Motivational Meeting \#1, 20 $(69 \%)$ attended transit training, $28(97 \%)$ attended a one-on-one meeting with an activity coach, $25(86 \%)$ attended Motivational Meeting \#2, and 26 (90\%) attended Motivational Meeting \#3. For the scheduled weekly telephone check-ins with their activity coach, $11(38 \%)$ completed all 12 check-ins, 13 (45\%) completed most (8-11) check-ins, four (14\%) completed some (four to seven) check-ins, and one (3\%) completed no check-ins. For the weekly activity logs, $13(45 \%)$ completed activity logs for all 12 weeks, nine $(31 \%)$ completed activity logs for $8-11$ weeks, one $(3 \%)$ completed activity logs for 4-7 weeks, and 6 (21\%) did not complete any activity logs. 


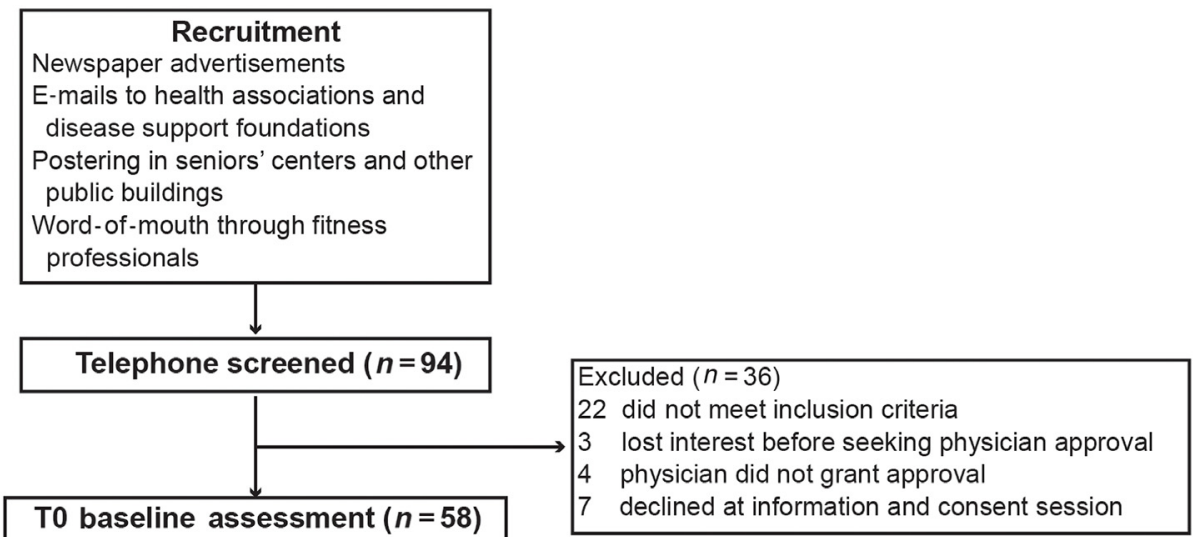

51 vaild accelerometry data

56 vaild travel diary data

58 vaild assessment data

\section{Allocated to intervention group $(n=29)$}

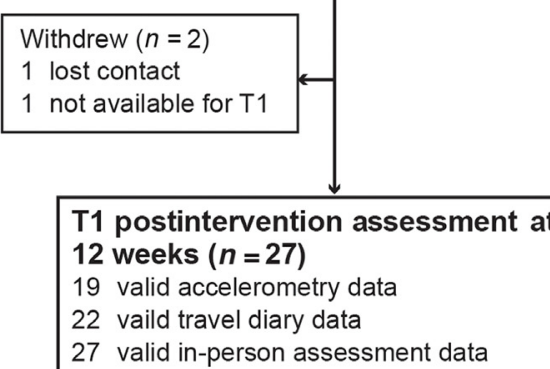

Withdrew $(n=2)$

2 not available for $T 2$

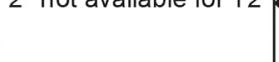

T2 follow-up asse

24 weeks $(n=25)$

18 valid accelerometry data

24 vaild travel diary data

25 valid in-person assessment data

Participants were ON intervention TO to T1 and OFF intervention $\mathrm{T} 1$ to $\mathrm{T} 2$.

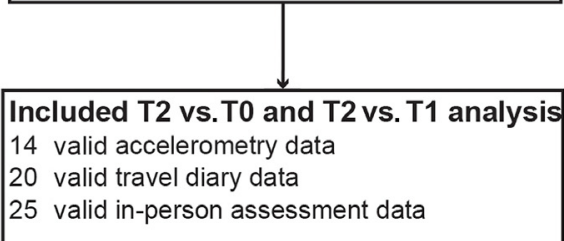

Allocated to control group $(n=29)$

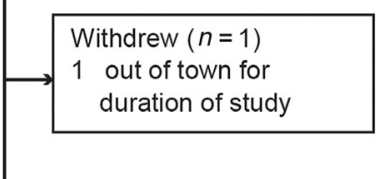

T1 postintervention assessment at 12 weeks $(n=28)$

25 valid accelerometry data

26 vaild travel diary data

28 valid in-person assessment data

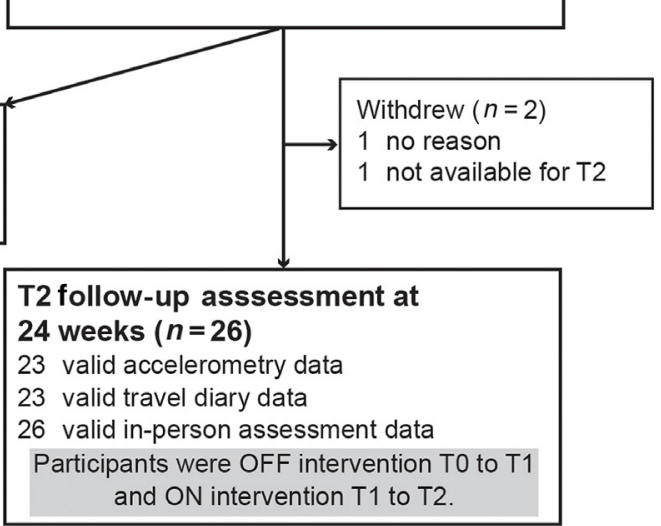

Figure 1 - Participant flow chart for the Men on the Move study following the consolidated standards of reporting trials guidelines.

\section{Physical Activity and Active Transportation Choices}

Men assigned to INT chose a wide range of physical activities for their personal action plans (Table 2; choices of CON presented for comparison). Among group-based activities, the most commonly chosen activities at community centers were group exercise classes $(n=14,50 \%)$, dance $(n=5,18 \%)$, and yoga $(n=2,7 \%)$, and at locations other than community centers were walk-to-run programs $(n=3,11 \%)$ and golfing $(n=2,7 \%)$. Among individual 
Table 1 Baseline Characteristics of Participants in the Men on the Move Study

\begin{tabular}{|c|c|c|c|}
\hline & Intervention $(n=29)$ & Waitlist control $(n=29)$ & Overall $(N=58)$ \\
\hline Age (years) & $71.8(6.5)$ & $72.0(6.9)$ & $71.9(6.6)$ \\
\hline Weight (kg) & $86.0(17.2)$ & $79.6(14.8)$ & $82.8(16.3)$ \\
\hline $\mathrm{BMI}\left(\mathrm{kg} / \mathrm{m}^{2}\right)$ & $28.4(5.0)$ & $26.9(4.6)$ & $27.7(4.8)$ \\
\hline \multicolumn{4}{|l|}{ Ethnicity, $n(\%)$} \\
\hline European & $16(55.2)$ & $20(69)$ & $36(62.1)$ \\
\hline Chinese & $5(17.2)$ & $7(24.1)$ & $12(20.7)$ \\
\hline other & $8(27.6)$ & $2(6.9)$ & $10(17.2)$ \\
\hline Foreign born, $n(\%)$ & $18(62.1)$ & $11(37.9)$ & $29(50)$ \\
\hline Time in Canada among foreign born (years) & $46.1(10.6)$ & $45.9(8.4)$ & $46(9.6)$ \\
\hline Live alone, $n(\%)$ & $7(24.1)$ & $11(37.9)$ & $18(31)$ \\
\hline Married/common law, $n(\%)$ & $20(69)$ & $16(55.2)$ & $37(63.8)$ \\
\hline Driver's license, $n(\%)$ & $27(93.1)$ & $29(100)$ & $56(96.6)$ \\
\hline Access to car, $n(\%)$ & $27(93.1)$ & $26(89.7)$ & $53(91.4)$ \\
\hline Some university education or greater, $n(\%)$ & $19(65.5)$ & $20(69)$ & $39(67.2)$ \\
\hline Time in current neighborhood (years) & $20.8(15.8)$ & $25.8(18.5)$ & $23.3(17.2)$ \\
\hline Own residence, $n(\%)$ & $18(62.1)$ & $17(58.6)$ & $35(60.3)$ \\
\hline Somewhat/very much like to walk outside, $n(\%)$ & $21(72.4)$ & $23(79.4)$ & $44(75.9)$ \\
\hline Somewhat/very much confident walking in neighborhood, $n(\%)$ & $24(82.8)$ & $26(89.6)$ & $50(86.2)$ \\
\hline Difficulty walking $1 / 4$ mile, $n(\%)$ & $7(26.9)$ & $1(4.2)$ & $8(16.0)$ \\
\hline Difficulty walking up 10 steps without rest, $n(\%)$ & $4(16)$ & $0(0)$ & $4(8.2)$ \\
\hline \multicolumn{4}{|l|}{ Days of physical activity ( $\geq 30 \mathrm{~min})$ in past week, $n(\%)$} \\
\hline 0 & $9(37.5)$ & $8(33.3)$ & $17(35.4)$ \\
\hline $1-4$ & $11(45.8)$ & $12(50)$ & $23(39.7)$ \\
\hline $5-7$ & $4(16.7)$ & $4(16.7)$ & $8(16.7)$ \\
\hline Retired or not working, $n(\%)$ & $26(89.7)$ & $18(62.1)$ & $44(75.9)$ \\
\hline \multicolumn{4}{|l|}{ Annual household income, $n(\%)$} \\
\hline$<\$ 25,000$ & $9(31)$ & $11(37.9)$ & $20(34.5)$ \\
\hline$\$ 25,000-\$ 49,999$ & $8(27.6)$ & $7(24.1)$ & $15(25.7)$ \\
\hline$>\$ 50,000$ & $12(41.4)$ & $11(37.9)$ & $23(39.6)$ \\
\hline \multicolumn{4}{|l|}{ Limited in getting out and about in one's neighborhood by, $n(\%)$} \\
\hline health reasons & $8(27.6)$ & $1(3.4)$ & $9(15.5)$ \\
\hline personal finances & $5(17.2)$ & $2(6.9)$ & $7(12.1)$ \\
\hline limited access to car & $2(6.9)$ & $2(6.9)$ & $4(6.9)$ \\
\hline emotional reasons & $1(3.4)$ & $3(10.3)$ & $4(6.9)$ \\
\hline caregiving or family responsibilities & $3(10.3)$ & $1(3.4)$ & $4(6.9)$ \\
\hline other & $2(6.9)$ & $2(6.9)$ & $4(6.9)$ \\
\hline \multicolumn{4}{|l|}{ Medical history, $n(\%)$} \\
\hline arthritis (rheumatoid or osteoarthritis) & $9(31.0)$ & $6(20.7)$ & $15(25.9)$ \\
\hline diabetes (Type I or II) & $5(17.2)$ & $4(13.8)$ & $9(15.5)$ \\
\hline anxiety or panic disorders & $1(3.4)$ & $6(20.7)$ & $7(12.1)$ \\
\hline osteoporosis & $3(10.3)$ & $2(6.9)$ & $5(8.6)$ \\
\hline COPD, ARDS, or emphysema & $3(10.3)$ & $2(6.9)$ & $5(8.6)$ \\
\hline depression & $2(6.9)$ & $3(10.3)$ & $5(8.6)$ \\
\hline congestive heart failure & $4(13.8)$ & $0(0)$ & $4(6.9)$ \\
\hline other & $8(27.6)$ & $1(3.4)$ & $9(15.5)$ \\
\hline Number of chronic conditions & $1.83(1.65)$ & $1.34(1.42)$ & $1.61(1.54)$ \\
\hline Fallen in the past 6 months, $n(\%)$ & $4(13.8)$ & $7(24.1)$ & $11(19.0)$ \\
\hline Pittsburgh Fatigability Scale physical score (/50) & $20.2(8.8)$ & $15.1(8.2)$ & $17.7(8.8)$ \\
\hline Falls efficacy (16-64) & $21.0(17.0-27.0)$ & $19.0(17.0-21.0)$ & $19.0(17.0-23.75)$ \\
\hline
\end{tabular}

Note. Cells contain mean $(S D)$ for normally distributed continuous variables, mean (25\%tile-75\%tile) for skewed continuous variables, and $n(\%)$ for categorical variables. $\mathrm{BMI}=$ body mass index; $\mathrm{ARDS}=$ acute respiratory distress syndrome; $\mathrm{COPD}=$ chronic obstructive pulmonary disease . 
Table 2 Physical Activity Choices Made by Men on the Move Participants in Their Personal Action Plans

\begin{tabular}{|c|c|c|c|}
\hline & Intervention $(n=28)$ & Waitlist control $(n=27)$ & Overall $(N=55)$ \\
\hline \multicolumn{4}{|c|}{ Community center, group, $n(\%)$} \\
\hline exercise class & $14(50.0)$ & $16(59.3)$ & $30(54.5)$ \\
\hline dance & $5(17.9)$ & $7(25.9)$ & $12(21.8)$ \\
\hline tai chi & $1(3.6)$ & $5(18.5)$ & $6(10.9)$ \\
\hline yoga & $2(7.1)$ & $3(11.1)$ & $5(9.1)$ \\
\hline other $^{\mathrm{a}}$ & $3(10.7)$ & $4(14.8)$ & $7(12.7)$ \\
\hline \multicolumn{4}{|c|}{ Community center, individual, $n(\%)$} \\
\hline fitness center & $17(60.7)$ & $15(55.6)$ & $32(58.2)$ \\
\hline swimming & $5(17.9)$ & $5(18.5)$ & $10(18.2)$ \\
\hline badminton & $1(3.6)$ & $3(11.1)$ & $4(7.3)$ \\
\hline pickleball & $1(3.6)$ & $3(11.1)$ & $4(7.3)$ \\
\hline other $^{\mathrm{b}}$ & $2(7.1)$ & $4(14.8)$ & $6(10.9)$ \\
\hline \multicolumn{4}{|c|}{ Noncommunity center, group, $n(\%)$} \\
\hline walk-to-run program & $3(10.7)$ & $0(0)$ & $3(5.5)$ \\
\hline golfing & $2(7.1)$ & $0(0)$ & $2(3.6)$ \\
\hline other $^{c}$ & $1(3.6)$ & $2(7.4)$ & $3(5.5)$ \\
\hline \multicolumn{4}{|c|}{ Noncommunity center, individual, $n(\%)$} \\
\hline walking & $20(71.4)$ & $21(77.8)$ & $41(74.5)$ \\
\hline stretching and meditation & $5(17.9)$ & $5(18.5)$ & $10(18.2)$ \\
\hline outdoor cycling & $3(10.7)$ & $5(18.5)$ & $9(16.4)$ \\
\hline stationary cycling at home & $3(10.7)$ & $1(3.7)$ & $4(7.3)$ \\
\hline strength training at home & $2(7.1)$ & $3(11.1)$ & $5(9.1)$ \\
\hline other $^{\mathrm{d}}$ & $6(21.4)$ & $11(40.7)$ & $17(30.9)$ \\
\hline \multicolumn{4}{|c|}{$\begin{array}{l}\text { Note. Activity choices were missing for one intervention and two waitlist control participants who did not attend a one-on-one consultation } \\
\text { with an activity coach. } \\
\text { a Includes indoor/mall walking group, chair yoga, pilates, and spin cycle. } \\
{ }^{b} \text { Includes ping pong, foam tennis, and volleyball. } \\
\text { cIncludes aerobic disc, cardiac rehabilitation, and ice hockey. } \\
{ }^{\mathrm{d}} \text { Includes hiking, canoeing, jogging, pool walking, boxing, chair exercises at home, kayaking, skating, skip rope, snow shoeing, tennis, and } \\
\text { treadmill at home. }\end{array}$} \\
\hline
\end{tabular}

activities, the most commonly chosen activities at community centers were using resistance or aerobic exercise machines $(n=17$, $61 \%)$, and swimming $(n=5,18 \%)$. Choices at locations other than community centers were walking $(n=20,71 \%)$, cycling outdoors or at home $(n=6,21 \%)$, and stretching and meditation $(n=5,18 \%)$.

Destinations most commonly selected for active transportation in personal action plans were parks $(n=10,36 \%)$, cities $(n=8$, $29 \%)$, shops/restaurants $(n=7,25 \%)$, downtown Vancouver $(n=5$, $18 \%)$, and the airport $(n=5,18 \%$; Table 3 , choices of CON presented for comparison). Other less commonly selected destinations included libraries/museums, recreation centers, and family member residences. Transit was the predominant transportation mode, with $75 \%(n=21)$ choosing public transit to reach at least one destination. The next most common mode was walking $(n=2$, $7 \%$ ). Men planned to travel alone to most destinations rather than with others.

\section{Intervention Effects on Health Outcomes}

Self-reported physical activity by CHAMPS. At T1, INT engaged in 7.2 more physical activities (95\% CI [1.5, 13.0] per week), including 5.2 more MVPAs (95\% CI $[1.7,8.6]$ per week), after controlling for T0 values (Table 4). Over the 12-week intervention, the number of all physical activities increased in INT from 19.9 to 26.2 per week, whereas it decreased in CON from 20.6 to 19.3 per week. The number of MVPAs increased in INT from 6.9 to 13.0 per week and increased in CON from 7.3 to 8.1 per week (Table 4). At T1, INT had 1,937 more kcal of energy expenditure from all physical activities (95\% CI [290, 3,584] kcal/week), including 1,493 more kcal of energy expenditure from MVPAs $(95 \% \mathrm{CI}$ [221, 2,648] kcal/week), compared with CON, after controlling for T0 values (Table 4).

Objectively measured physical activity by accelerometry. After adjusting for T0 values, INT achieved more MVPA at T1 than CON (mean: 9.0, 95\% CI [-0.21, 18.20] min/day; Table 4). This was realized almost entirely through a group difference in moderate (not vigorous) activity (mean: $8.9,95 \%$ CI $[-0.47,18.28] \mathrm{min} /$ day) Over the 12-week intervention, MVPA increased in INT from 28.5 to $32.2 \mathrm{~min} /$ day, whereas it decreased in $\mathrm{CON}$ from 27.3 to $22.4 \mathrm{~min} /$ day. At T1, INT accumulated 1,140 more steps $(95 \%$ CI [51-2,229] per day), after adjusting for T0 values (Table 4). Over the 12-week intervention, steps decreased slightly in INT from 6,802 to 6,738 per day and decreased more substantially in CON from 6,378 to 5,265 per day. At T1, INT was 3.27 times more 
Table 3 Active Transportation Destinations Chosen by Men on the Move Participants in Their Personal Action Plans

\begin{tabular}{|c|c|c|c|}
\hline & Intervention $(n=28)$ & Waitlist control $(n=25)$ & Overall $(N=53)$ \\
\hline \multicolumn{4}{|l|}{ Destination, $n(\%)$} \\
\hline park & $10(35.7)$ & $9(36.0)$ & $19(35.8)$ \\
\hline cities & $8(28.6)$ & $7(28.0)$ & $15(28.3)$ \\
\hline downtown & $5(17.9)$ & $8(32.0)$ & $13(24.5)$ \\
\hline shop/restaurant & $7(25.0)$ & $6(24.0)$ & $13(24.5)$ \\
\hline airport & $5(17.9)$ & $4(16.0)$ & $9(16.9)$ \\
\hline library/museum & $4(14.3)$ & $5(20.0)$ & $9(16.9)$ \\
\hline recreation center & $4(14.3)$ & $4(16.0)$ & $8(15.1)$ \\
\hline family member's residence & $2(7.1)$ & $1(4.0)$ & $3(5.7)$ \\
\hline
\end{tabular}

likely than $\mathrm{CON}$ to meet national physical activity guidelines of 150 min or more per week of MVPA accumulated in bouts of 10 min or longer (42.1\% vs. $16.0 \%$; $95 \%$ CI $[0.75,16.3]$; Table 4$)$.

There were no suggested group differences at T1 in LPA (min/day), time spent in sedentary behavior (min/day or percentage of day), or MVPA (min/day) with bout duration of at least $10 \mathrm{~min}$ (Table 4).

Active transportation. At T1, INT was 4.24 times more likely than CON to take at least one transit trip/week (95\% CI [1.19, 17.98]; Table 4). There were no suggested differences between INT and $\mathrm{CON}$ at $\mathrm{T} 1$ in rates of total trips, car trips, active trips, transit trips, or walking trips (Table 4).

Mobility. There were no suggested differences at T1 between INT and CON in composite life-space mobility score, SPPB score, or gait speed (Table 4).

\section{Retention of Intervention Effects on Health Outcomes}

Self-reported physical activity by CHAMPS. At T2, INT continued to engage in more MVPAs than at T0 (10.0 vs. 6.9/week), but fewer than at T1 (13.0/week; Table 5). By contrast, total number of physical activities at T2 did not appear to be different than at T0 (23.6 vs. 19.4/week) or T1 (26.2/week; Table 5). At T2, INT had greater energy expenditure from all physical activities than at T0 (5,162 vs. $2,627 \mathrm{kcal} /$ week), and a similar amount as at T1 (5,058 kcal/week; Table 5). Similarly, at T2, INT also had greater energy expenditure from MVPAs than at T0 (3,205 vs. $1,787 \mathrm{kcal} /$ week), and a similar amount as at $\mathrm{T} 1(3,031 \mathrm{kcal} /$ week; Table 5).

Objectively measured physical activity by accelerometry. At T2, INT continued to achieve more MVPA than at T0 (35.9 vs. $30.3 \mathrm{~min} /$ day), and a similar amount as at T1 (36.0 min/day; Table 5). At T2, INT accumulated 7,842 steps/day, which did not appear different than at T0 (7,281 steps/day) or T1 (7,496 steps/day; Table 5). The proportion of INT meeting national physical activity guidelines at T2 $(28.6 \%)$ was the same as at T0 $(28.6 \%)$ and fewer than at T1 (50.0\%; Table 5).

Active transportation. The proportion of INT taking at least one transit trip/week at T1 $(60.0 \%)$ did not appear to be different from T0 $(45.0 \%)$ or T1 values $(65.0 \%$; Table 5$)$.

\section{Discussion}

This feasibility trial of the Men on the Move intervention is among few physical activity intervention programs for older men. As such, it addresses the call for physical activity intervention research to include more diverse older adult samples (Chase, 2015). Older men are largely underrepresented in physical activity intervention studies, and interventions designed specifically for older men are rare. A recent meta-analysis of 104 studies of physical activity interventions for older adults reported that women comprised $83 \%$ of study samples on average, and no interventions were designed and conducted exclusively for older men (Chase, 2015).

We observed high rates of recruitment, retention, and adherence to Men on the Move, which exceeded our predetermined targets. Specifically, $62 \%$ of individuals who responded to study advertisements ultimately enrolled in the study, 95\% who enrolled returned for $\mathrm{T} 1$ assessments, and $88 \%$ returned for $\mathrm{T} 2$ assessments. During the intervention phase, attendance at one-on-one activity coach consultations was $97 \%$, motivational meetings was $\geq 85 \%$, and weekly telephone calls (at least eight of 12 calls) was $83 \%$. The flexible nature of the intervention and our results support the scalability of our intervention and its feasibility (Thabane et al., 2010) for scale-up.

The Men on the Move intervention appeared to improve physical activity relative to control. Specifically, the intervention led to suggested increases in all self-reported and some objective measures of physical activity, with those in the INT group 3.3 times more likely to meet physical activity guidelines. Given the inextricable link between physical activity, mobility, and older adult independence (Webber, Porter, \& Menec, 2010), and the common finding of decreased physical activity with age (Buchman et al., 2014), our results are encouraging. Intervention-induced increases in MVPA were exclusively the result of increased moderateintensity activity; overall, men engaged in very small amounts vigorous physical activity before or after the intervention. Walking was the most commonly chosen activity, consistent with the notion that walking is a highly accessible and affordable activity for older adults. Although less is known about the benefits of light-intensity physical activity than MVPA, the traditional focus on MVPA may limit our understanding of the health benefits of the full range of physical activity intensities (Lee \& Shiroma, 2014). Light-intensity physical activity was positively associated with self-reported health and well-being (Buman et al., 2010), and many older adults engage 
Table 4 Physical Activity, Active Transportation, and Mobility Outcomes From the Men on the Move Study

\begin{tabular}{|c|c|c|c|c|c|c|}
\hline & \multicolumn{2}{|c|}{ INT group } & \multicolumn{2}{|c|}{ CON group } & \multicolumn{2}{|c|}{$\begin{array}{l}\text { T0 adjusted } \\
\text { group difference } \\
\text { (INT - CON) at T1 }\end{array}$} \\
\hline & T0 & T1 & TO & T1 & Mean & {$[95 \% \mathrm{Cl}]$} \\
\hline \multicolumn{7}{|l|}{ Physical activity } \\
\hline \multicolumn{7}{|l|}{ CHAMPS $^{\mathrm{a}}$} \\
\hline all PAs (\#/week) & $19.9(10.9)$ & $26.2(12.4)$ & $20.6(17.4)$ & $19.3(13.9)$ & 7.2 & {$[1.5,13.0]$} \\
\hline MVPAs, (\#/week) & $6.9(7.3)$ & $13.0(7.4)$ & $7.3(9.1)$ & $8.1(9.2)$ & 5.2 & {$[1.7,8.6]$} \\
\hline EE from all PAs (kcal/week) & $3,637(2,806)$ & $5,058(3,826)$ & $3,829(3,535)$ & $3,313(3,439)$ & 1,937 & {$[290,3,584]$} \\
\hline EE from MVPAs (kcal/week) & $1,787(2,312)$ & $3,031(2,836)$ & $2,136(2,803)$ & $1,822(2,713)$ & 1,434 & {$[221,2,648]$} \\
\hline \multicolumn{7}{|l|}{ Accelerometry $^{\mathrm{b}}$} \\
\hline MVPA (min/day) & $28.5(21.9)$ & $32.2(21.4)$ & $27.3(19.5)$ & $22.4(18.4)$ & 9.0 & {$[-0.2,18.2]$} \\
\hline MVPA, $\geq 10$ min bouts (min/day) & $15.0(18.8)$ & $17.5(18.4)$ & $12.3(14.6)$ & $10.7(14.4)$ & 5.4 & {$[-3.5,14.4]$} \\
\hline MPA (min/day) & $27.5(22.5)$ & $31.5(21.0)$ & $26.8(19.2)$ & $22.1(18.0)$ & 8.9 & {$[-0.5,18.3]$} \\
\hline LPA (min/day) & $230.5(83.9)$ & $262.9(91.6)$ & $218.9(75.0)$ & $191.0(66.7)$ & 16.0 & {$[-10.4,42.3]$} \\
\hline sedentary behavior (min/day) & $544.0(72.1)$ & $548.9(72.2)$ & $586.9(82.3)$ & $596.8(135.5)$ & -2.1 & {$[-54.4,50.1]$} \\
\hline $\begin{array}{l}\text { sedentary behavior } \\
\text { (percentage of day) }\end{array}$ & $68.3(9.8)$ & $69.5(9.9)$ & $70.6(9.1)$ & $73.3(9.7)$ & -1.7 & {$[-4.9,1.5]$} \\
\hline steps (\#/day) & $6,802(3,587)$ & $6,738(3,371)$ & $6,378(2,608)$ & $5,265(2,536)$ & 1,140 & {$[51,2,229]$} \\
\hline & & & & & Odds ratio & {$[95 \% \mathrm{CI}]$} \\
\hline $\begin{array}{l}\text { met MVPA guidelines } \\
(\geq 150 \mathrm{~min} / \text { week in } 10+\text { min bouts }) \\
n(\%)\end{array}$ & $5(29.4)$ & $7(41.2)$ & $5(21.7)$ & $4(17.4)$ & 3.27 & {$[0.75,16.33]$} \\
\hline Active transportation ${ }^{c}$ & & & & & Relative rate & {$[95 \% \mathrm{CI}]$} \\
\hline total trips (\#/day) & $4.2(1.6)$ & $3.9(1.4)$ & $3.9(1.8)$ & $3.5(1.4)$ & 1.08 & {$[0.92,1.26]$} \\
\hline car trips (\#/day) & $2.3(2.2)$ & $2.1(1.6)$ & $2.0(1.8)$ & $2.0(1.6)$ & 1.00 & {$[0.61,1.67]$} \\
\hline active trips (\#/day) & $1.5(1.2)$ & $1.6(1.2)$ & $1.6(1.5)$ & $1.5(1.3)$ & 1.09 & {$[0.70,1.70]$} \\
\hline transit trips (\#/day) & $0.0(0-0.3)$ & $0.6(0.0-0.7)$ & $0.1(0.0-0.68)$ & $0.0(0.0-0.3)$ & 1.67 & {$[0.58,4.99]$} \\
\hline \multirow[t]{2}{*}{ walking trips (\#/day) } & $1.4(1.2)$ & $1.2(0.9)$ & $1.6(1.6)$ & $1.3(1.1)$ & 1.07 & {$[0.7,1.7]$} \\
\hline & & & & & Odds ratio & {$[95 \% \mathrm{CI}]$} \\
\hline$\geq 1$ transit trip/week, $n(\%)$ & $9(42.9)$ & $13(61.9)$ & $15(57.7)$ & $9(34.6)$ & 4.24 & {$[1.19,17.98]$} \\
\hline Mobility $^{\mathrm{a}}$ & & & & & Mean & {$[95 \% \mathrm{CI}]$} \\
\hline life-space mobility, /120 & $71.1(19.9)$ & $76.9(16.7)$ & $73.9(20.2)$ & $75.6(19.3)$ & 2.6 & {$[-5.4,10.7]$} \\
\hline gait speed $(\mathrm{m} / \mathrm{s})$ & $0.99(0.21)$ & $1.12(0.22)$ & $1.05(0.19)$ & $1.14(0.19)$ & 0.03 & {$[-0.06,0.12]$} \\
\hline $\operatorname{SPPB}(/ 12)$ & $10.0(8.0-11.0)$ & $11.0(9.5-12.0)$ & $11.0(11.0-12.0)$ & $11.0(11.0-12.0)$ & - & - \\
\hline
\end{tabular}

Note. Only participants who provided valid data points at both $\mathrm{T} 0$ and $\mathrm{T} 1$ were included. $\mathrm{INT}=$ intervention group; $\mathrm{CON}=$ waitlist control group; $\mathrm{CHAMPS}=\mathrm{Community}$ Healthy Model Program for Seniors; PAs = physical activities; MVPA = moderate-vigorous physical activity; MPA = moderate physical activity; LPA = light physical activity; $\mathrm{CI}=$ confidence interval; $\mathrm{OR}=$ odds ratio; $\mathrm{SPPB}=$ short physical performance battery; $\mathrm{EE}=$ energy expenditure.

${ }^{\text {a }}$ Sample size for intervention was $n=27$, for control was $n=28$.

${ }^{\mathrm{b}}$ Sample size for intervention was $n=17$, for control was $n=23$.

${ }^{\mathrm{c}}$ Sample size for intervention was $n=21$, for control was $n=26$.

only in LPA; thus, it seems prudent for future research to report the full range of physical activity intensities for older adults.

Many positive effects of the intervention observed at T1 appeared to be retained at T2: MVPA (\#/week and min/day), moderate physical activity (min/day), and energy expenditure (kcal/week). As a result, men were generally achieving more physical activity at $\mathrm{T} 2$ than at T0, but less than at T1, suggesting a moderate degree of lasting and positive behavior change. The intervention incorporated cognitive strategies (e.g., education, consultation) and behavioral strategies (e.g., planning to overcome barriers, goal setting, selfmonitoring) that are associated with effectiveness among older adults (Chase, 2015). These likely contributed to the initial and sustained impacts of the intervention.
The intervention also resulted in a suggested increase in the odds of taking public transportation, which is a form of active transportation. We contend the impact of the intervention on public transportation use would likely be larger in populations where fewer men have a driver's license or access to a vehicle. These results suggest that offering a combination of group transit training, personal travel planning, and complimentary transit passes might be considered at scale-up in urban areas with accessible public transportation systems.

We designed Men on the Move to be a scalable physical activity intervention to increase the potential to improve population health over the long-term. In particular, the intervention is flexible and tailored to the needs, interests, and resources of men; focuses on 
Table 5 Retention of Physical Activity and Active Transportation Outcomes in Men on the Move Among the Intervention Group

\begin{tabular}{|c|c|c|c|c|c|c|c|}
\hline & \multicolumn{3}{|c|}{ Mean (SD) } & \multicolumn{2}{|c|}{ T2 vs. T0 difference } & \multicolumn{2}{|c|}{ T2 vs. T1 difference } \\
\hline & TO & T1 & T2 & Mean & {$[95 \% \mathrm{Cl}]$} & Mean & {$[95 \% \mathrm{Cl}]$} \\
\hline \multicolumn{8}{|l|}{ Physical activity } \\
\hline \multicolumn{8}{|l|}{ CHAMPS $^{\mathrm{a}}$} \\
\hline EE from all PAs (kcal/week) & $3,637(2,806)$ & $5,058(3,826)$ & $5,162(3,938)$ & 1,421 & {$[195,2,881]$} & 104 & {$[-784,1,375]$} \\
\hline EE from MVPAs (kcal/week) & $1,787(2,312)$ & $3,031(2,836)$ & $3,205(2,995)$ & 1,418 & {$[194,2,535]$} & 174 & {$[-560,978]$} \\
\hline all PAs (\#/week) & $19.9(10.9)$ & $26.2(12.4)$ & $23.5(11.3)$ & 3.5 & {$[-1.0,8.4]$} & -2.7 & {$[-7.1,2.2]$} \\
\hline MVPAs (\#/week) & $6.9(7.3)$ & $13.0(7.4)$ & $10.0(6.3)$ & 3.2 & {$[0.77,5.65]$} & -2.9 & {$[-5.5,-0.6]$} \\
\hline \multicolumn{8}{|l|}{ Accelerometry $^{\mathrm{b}}$} \\
\hline MVPA (min/day) & $30.3(21.2)$ & $36.0(21.2)$ & $35.9(25.8)$ & 5.6 & {$[-0.6,11.8]$} & 0.0 & {$[-10.5,10.4]$} \\
\hline MPA (min/day) & $29.1(22.0)$ & $35.1(20.9)$ & $35.7(25.8)$ & 6.6 & {$[-0.4,13.5]$} & 0.6 & {$[-9.6,10.7]$} \\
\hline steps (\#/day) & $7,281(3,491)$ & $7,496(3,106)$ & $7,842(4,118)$ & 591 & {$[-448,1,569]$} & 346 & {$[-1,264,1,955]$} \\
\hline $\begin{array}{l}\text { met MVPA guidelines } \\
\text { ( } \geq 150 \mathrm{~min} / \text { week }), n(\%)\end{array}$ & 11 & $7(50.0)$ & $4(28.6)$ & $0(0.0)$ & - & $-3(21.4)$ & - \\
\hline \multicolumn{8}{|l|}{ Active transportation ${ }^{\mathrm{c}}$} \\
\hline$\geq 1$ transit trip/week, $n(\%)$ & $9(45.0)$ & $13(65.0)$ & $12(60.0)$ & $3(15.0)$ & - & $-1(5.0)$ & - \\
\hline
\end{tabular}

Note. Only participants in the intervention group who provided valid data for all three assessment sessions (T0, T1, and T2) were included. Thus, in some instances, the mean and $S D$ differ slightly from those reported in Table 4. CHAMPS = Community Healthy Model Program for Seniors; MVPA = moderate-vigorous physical activity; $\mathrm{MPA}=$ moderate physical activity; $\mathrm{CI}=$ confidence interval; $\mathrm{PAs}=$ physical activities; $\mathrm{EE}=$ energy expenditure .

${ }^{\text {a }}$ Sample size was $n=25$.

${ }^{\mathrm{b}}$ Sample size was $n=14$.

${ }^{\mathrm{c}}$ Sample size was $n=20$.

leveraging existing resources for physical activity within a community, and builds capacity among older men to use active forms of transportation. Our approach highlights the importance of building partnerships with community organizations - a central tenet of implementation at scale - to support long-term sustainability (Yamey, 2011). There are very few examples of scaled-up physical activity interventions, particularly for older adults-a recent systematic review identified just two (Reis et al., 2016). Designing interventions with scalability in mind improves the likelihood of successfully delivering the intervention at scale.

Maintenance and sustainability of an intervention requires that it become embedded into systems (Reis et al., 2016). There are inherent challenges to delivering interventions at scale (Wandersman et al., 2008), but relatively little has been reported about this. Thus, the knowledge and experience we share regarding design, implementation, and evaluation of Men on the Move has substantial value. Indeed, our intervention and results have served to inform design and implementation at scale, as well as evaluation methods, of a choicebased physical activity promotion model for older men and women, Choose to Move, that is being delivered across the province of British Columbia, Canada. The provincial program Choose to Move retains the elements of Men on the Move deemed essential by participants and community partners (e.g., flexibility, group sessions that promote social interaction, and trusted relationships between participants and activity coaches). However, to manage program costs and support sustainability, the provincial program has also been adapted during phases of scale-up (e.g., less frequent telephone support from activity coaches, no provision of complimentary recreation, or transit passes or pedometers). We are currently evaluating impact and implementation of Choose to Move and developing sustainability approaches with reduced cost in mind.

The Men on the Move intervention did not appear to impact measures of mobility including SPPB, gait speed, or life space. The intervention did not specifically encourage men to participate in activities that would increase lower extremity strength, balance, or speed; future versions of the intervention could specifically recommend resistance and balance exercises, consistent with national physical activity guidelines (Tremblay et al., 2011). In addition, median SPPB values at T0 in INT and CON were indicative of very good lower extremity physical function, so there was limited potential for improvement. Future trials would benefit from including other measures of capacity for mobility, such as a $400-\mathrm{m}$ walk time (Simonsick et al., 2008) that would not be susceptible to ceiling effects and/or modified screening to enroll older men with poorer physical function, as done by the LIFE Trial (Pahor et al., 2014). Furthermore, although the intervention encouraged more frequent physical activity, there were no specific recommendations to venture further from one's home or to travel more independently; hence, the lack of change in life-space mobility.

This study has certain limitations. First, participants had higher levels of baseline physical activity (25\% achieved $\geq 150 \mathrm{~min}$ of MVPA) than national samples (Colley et al., 2011). Thus, we recommend different and more targeted recruitment strategies in the future to reach exclusively inactive and more marginalized (e.g., frailer) populations of older men who have greater need for and may receive greater benefit from this type of intervention. Second, we used typical recruitment strategies for physical activity intervention trials, and therefore, do not know how many individuals were reached by study advertisements (the denominator of the study) and cannot quantify a screening rate (\# screened/\# reached). A very small screening rate would diminish scalability if these were the only recruitment strategies used. However, additional and more targeted strategies would be appropriate to facilitate broad scale-up. For example, since conducting Men on the Move, we have developed a range of referral channels into our scaled-up provincial program, Choose to Move, including partnerships with service sector organizations, primary care networks, and nongovernment organizations that serve the needs of older adults. Third, given that 
the strength of the intervention effects on physical activity tended to diminish during follow-up, future research is warranted to investigate whether and how much additional contact between participants and their activity coaches would increase sustainability of intervention effects. Finally, this study did not explore participant perceptions of the intervention on their health and well-being, but future qualitative work in this area will be important to optimize the design of lifestyle interventions for older men.

In conclusion, it was feasible to conduct a novel, flexible, and scalable 12-week choice-based intervention of physical activity and active transportation in older men. Rates of recruitment, retention, and adherence were high and exceeded predetermined targets. In addition, there were suggested increases in physical activity that appeared to be sustained for a short time after the intervention ceased, and in the likelihood of public transit use. Given the challenges of engaging older men in physical activity and their health (Caperchione et al., 2017), and the substantial benefits of physical activity to health should we succeed in doing so, we are encouraged by these findings.

\section{Acknowledgments}

This study was supported by a Team Grant in Boys' and Men's Health from the Canadian Institutes of Health Research (138295). D. C. Mackey and J. Sims-Gould were each supported by a Scholar Award from the Michael Smith Foundation for Health Research. J. Sims-Gould was also supported by a New Investigator Award from the Canadian Institutes of Health Research. The authors thank the study participants and three activity coaches: Kate Lee, Bonnie McCoy, and Kieu Nguyen.

\section{References}

Arain, M., Campbell, M.J., Cooper, C.L., \& Lancaster, G.A. (2010). What is a pilot or feasibility study? A review of current practice and editorial policy. BMC Medical Research Methodology, 10, 67. PubMed ID: 20637084 doi:10.1186/1471-2288-10-67

Ashe, M.C., Winters, M., Hoppmann, C.A., Dawes, M., Gardiner, P.A., Giangregario, L.M., . . . McKay, H.A. (2015). "Not Just Another Walking Program"-Everyday activity supports you (EASY) modelA randomized pilot study for a parallel randomized controlled trial. Pilot and Feasibility Studies, 1(4), 1-12.

Baker, P.S., Bodner, E.V., \& Allman, R.M. (2003). Measuring life-space mobility in community-dwelling older adults. Journal of the American Geriatrics Society, 51(11), 1610-1614. PubMed ID: 14687391 doi:10.1046/j.1532-5415.2003.51512.x

Bauman, A., Merom, D., Bull, F.C., Buchner, D.M., \& Singh, M.A.F. (2016). Updating the evidence for physical activity: Summative reviews of the epidemiological evidence, prevalence, and interventions to promote "Active Aging." The Gerontologist, 56, S268-S280. PubMed ID: 26994266 doi:10.1093/geront/gnw031

Buchman, A.S., Wilson, R.S., Yu, L., James, B.D., Boyle, P.A., \& Bennett, D.A. (2014). Total daily activity declines more rapidly with increasing age in older adults. Archives of Gerontology and Geriatrics, 58(1), 74-79. PubMed ID: 24007938 doi:10.1016/j.archger. 2013.08.001

Buman, M.P., Hekler, E.B., Haskell, W.L., Pruitt, L., Conway, T.L., Cain, K.L., . . . King, A.C. (2010). Objective light-intensity physical activity associations with rated health in older adults. American Journal of Epidemiology, 172(10), 1155-1165. PubMed ID: 20843864 doi:10.1093/aje/kwq249
Caperchione, C.M., Bottorff, J.L., Oliffe, J.L., Johnson, S.T., Hunt, K., Sharp, P., . . Goldenberg, S.L. (2017). The HAT TRICK programme for improving physical activity, healthy eating and connectedness among overweight, inactive men: Study protocol of a pragmatic feasibility trial. British Medical Journal Open, 7(9), e016940. doi:10.1136/bmjopen-2017-016940

Chase, J.A.D. (2015). Interventions to increase physical activity among older adults: A meta-analysis. The Gerontologist, 55(4), 706-718. PubMed ID: 25298530 doi:10.1093/geront/gnu090

Chudyk, A.M., Winters, M., Moniruzzaman, M., Ashe, M.C., Gould, J.S., \& McKay, H. (2015). Destinations matter: The association between where older adults live and their travel behavior. Journal of Transport \& Health, 2(1), 50-57. PubMed ID: 27104147 doi:10.1016/j.jth. 2014.09.008

Colley, R.C., Garriguet, D., Janssen, I., Craig, C.L., Clarke, J., \& Tremblay, M.S. (2011). Physical activity of Canadian adults: Accelerometer results from the 2007 to 2009 Canadian Health Measures Survey. Health Reports, 22(1), 7-14. PubMed ID: 21510585

Das, P., \& Horton, R. (2016). Physical activity-Time to take it seriously and regularly. The Lancet, 388(10051), 1254-1255. PubMed ID: 27475269 doi:10.1016/S0140-6736(16)31070-4

Davis, M.G., Fox, K.R., Hillsdon, M., Coulson, J.C., Sharp, D.J., Stathi, A., \& Thompson, J.L. (2011). Getting out and about in older adults: The nature of daily trips and their association with objectively assessed physical activity. International Journal of Behavioral Nutrition and Physical Activity, 8, 116. doi:10.1186/1479-5868-8-116

Ding, D., \& Gebel, K. (2012). Built environment, physical activity, and obesity: What have we learned from reviewing the literature? Health \& Place, 18(1), 100-105. PubMed ID: 21983062 doi:10.1016/j .healthplace.2011.08.021

Ding, D., Lawson, K.D., Kolbe-Alexander, T.L., Finkelstein, E.A., Katzmarzyk, P.T., van Mechelen, W., . . . Executive, P.A.S. (2016). The economic burden of physical inactivity: A global analysis of major non-communicable diseases. The Lancet, 388(10051), 13111324. PubMed ID: 27475266 doi:10.1016/S0140-6736(16)30383-X

Durlak, J.A., \& DuPre, E.P. (2008). Implementation matters: A review of research on the influence of implementation on program outcomes and the factors affecting implementation. American Journal of Community Psychology, 41(3-4), 327-350. PubMed ID: 18322790 doi:10.1007/s10464-008-9165-0

Freedson, P.S., Melanson, E., \& Sirard, J. (1998). Calibration of the Computer Science and Applications, Inc. accelerometer. Medicine \& Science in Sports \& Exercise, 30(5), 777-781. doi:10.1097/ 00005768-199805000-00021

Gillespie, L.D., Robertson, M.C., Gillespie, W.J., Sherrington, C., Gates, S., Clemson, L.M., \& Lamb, S.E. (2012). Interventions for preventing falls in older people living in the community. Cochrane Database of Systematic Reviews, 9, CD007146.

Glynn, N.W., Santanasto, A.J., Simonsick, E.M., Boudreau, R.M., Beach, S.R., Schulz, R., \& Newman, A.B. (2015). The Pittsburgh Fatigability Scale for older adults: Development and validation. Journal of the American Geriatrics Society, 63(1), 130-135. PubMed ID: 25556993 doi:10.1111/jgs.13191

Gorman, E., Hanson, H.M., Yang, P.H., Khan, K.M., Liu-Ambrose, T., \& Ashe, M.C. (2014). Accelerometry analysis of physical activity and sedentary behavior in older adults: A systematic review and data analysis. European Review of Aging and Physical Activity, 11(1), 35-49. doi:10.1007/s11556-013-0132-x

Gough, B. (2013). The psychology of men's health: Maximizing masculine capital. Health Psychology, 32(1), 1-4. PubMed ID: 23316848 doi:10.1037/a0030424 
Groll, D.L., To, T., Bombardier, C., \& Wright, J.G. (2005). The development of a comorbidity index with physical function as the outcome. Journal of Clinical Epidemiology, 58(6), 595-602. PubMed ID: 15878473 doi:10.1016/j.jclinepi.2004.10.018

Guralnik, J.M., Simonsick, E.M., Ferrucci, L., Glynn, R.J., Berkman, L.F., Blazer, D.G., .. . Wallace, R.B. (1994). A short physical performance battery assessing lower extremity function: Association with selfreported disability and prediction of mortality and nursing home admission. Journal of Gerontology, 49(2), M85-M94. PubMed ID: 8126356 doi:10.1093/geronj/49.2.M85

Hatchell, A.C., Bassett-Gunter, R.L., Clarke, M., Kimura, S., \& Latimer-Cheung, A.E. (2013). Messages for men: The efficacy of EPPM-based messages targeting men's physical activity. Health Psychology, 32(1), 24-32. PubMed ID: 23316850 doi:10.1037/ a0030108

Hoffmann, T.C., Glasziou, P.P., Boutron, I., Milne, R., Perera, R., Moher, D., . . Michie, S. (2014). Better reporting of interventions: Template for intervention description and replication (TIDieR) checklist and guide. British Medical Journal, 348, g1687. PubMed ID: 24609605 doi:10.1136/bmj.g1687

Hunt, K., Wyke, S., Gray, C.M., Anderson, A.S., Brady, A., Bunn, C., . . . Treweek, S. (2014). A gender-sensitised weight loss and healthy living programme for overweight and obese men delivered by Scottish Premier League football clubs (FFIT): A pragmatic randomised controlled trial. The Lancet, 383(9924), 1211-1221. PubMed ID: 24457205 doi:10.1016/S0140-6736(13)62420-4

Kim, S. (2011). Transportation alternatives of the elderly after driving cessation. Transportation Research Record, 2265, 170-176. doi:10. 3141/2265-19

Lee, I.M., \& Shiroma, E.J. (2014). Using accelerometers to measure physical activity in large-scale epidemiological studies: Issues and challenges. British Journal of Sports Medicine, 48(3), 197-201. PubMed ID: 24297837 doi:10.1136/bjsports-2013-093154

Lee, I.M., Shiroma, E.J., Lobelo, F., Puska, P., Blair, S.N., Katzmarzyk, P.T., \& Lancet Physical Activity Series Working Group. (2012). Effect of physical inactivity on major non-communicable diseases worldwide: An analysis of burden of disease and life expectancy. Lancet, 380(9838), 219-229. PubMed ID: 22818936 doi:10.1016/ S0140-6736(12)61031-9

Mackey, D.C., Lui, L.Y., Cawthon, P.M., Ensrud, K., Yaffe, K., \& Cummings, S.R. (2016). Life-space mobility and mortality in older women: Prospective results from the study of osteoporotic fractures. Journal of the American Geriatrics Society, 64(11), 2226-2234. PubMed ID: 27696354 doi:10.1111/jgs.14474

Michie, S., Ashford, S., Sniehotta, F.F., Dombrowski, S.U., Bishop, A., \& French, D.P. (2011). A refined taxonomy of behaviour change techniques to help people change their physical activity and healthy eating behaviours: The CALO-RE taxonomy. Psychology \& Health, 26(11), 1479-1498. PubMed ID: 21678185 doi:10.1080/08870446. 2010.540664

Milat, A.J., King, L., Bauman, A.E., \& Redman, S. (2013). The concept of scalability: Increasing the scale and potential adoption of health promotion interventions into policy and practice. Health Promotion International, 28(3), 285-298. PubMed ID: 22241853 doi:10.1093/ heapro/dar097

Morency, C., Trepanier, M., \& Demers, M. (2011). Walking to transit: An unexpected source of physical activity. Transport Policy, 18(6), 800-806. doi:10.1016/j.tranpol.2011.03.010

National Health Service. (2011). Start active, stay active: A report on physical activity for health from the four home countries' Chief Medical Officers. London, UK: Department of Health and Social Care.
Pahor, M., Guralnik, J.M., Ambrosius, W.T., Blair, S., Bonds, D.E., Church, T.S., . . . LIFE Study Investigators. (2014). Effect of structured physical activity on prevention of major mobility disability in older adults: The LIFE study randomized clinical trial. Journal of the American Medical Association, 311(23), 2387-2396. PubMed ID: 24866862 doi:10.1001/jama.2014.5616

Reis, R.S., Salvo, D., Ogilvie, D., Lambert, E.V., Goenka, S., Brownson, R.C., \& Lancet Physical Activity Series 2 Executive Committee. (2016). Scaling up physical activity interventions worldwide: Stepping up to larger and smarter approaches to get people moving. The Lancet, 388(10051), 1337-1348. PubMed ID: 27475273 doi:10. 1016/S0140-6736(16)30728-0

Rissel, C., Curac, N., Greenaway, M., \& Bauman, A. (2012). Physical activity associated with public transport use-A review and modelling of potential benefits. International Journal of Environmental Research and Public Health, 9(7), 2454-2478. PubMed ID: 22851954 doi:10.3390/ijerph9072454

Simonsick, E.M., Newman, A.B., Visser, M., Goodpaster, B., Kritchevsky, S.B., Rubin, S., . . . Health, Aging and Body Composition Study. (2008). Mobility limitation in self-described well-functioning older adults: Importance of endurance walk testing. The Journals of Gerontology. Series A, Biological Sciences and Medical Sciences, 63(8), 841-847. doi:10.1093/gerona/63.8.841

Statistics Canada. (2017). Census Profile, 2016 Census. Retrieved from http://www12.statcan.gc.ca/census-recensement/2016/dp-pd/prof/index. cfm?Lang=E

Stepaniuk, J.A., Tuokko, H., McGee, P., Garrett, D.D., \& Benner, E.L. (2008). Impact of transit training and free bus pass on public transportation use by older drivers. Preventive Medicine, 47(3), 335-337. PubMed ID: 18440058 doi:10.1016/j.ypmed.2008. 03.002

Stewart, A.L., Grossman, M., Bera, N., Gillis, D.E., Sperber, N., Castrillo, M., . . . Cassady, D. (2006). Multilevel perspectives on diffusing a physical activity promotion program to reach diverse older adults. Journal of Aging and Physical Activity, 14(3), 270-287. PubMed ID: 17090805 doi:10.1123/japa.14.3.270

Stewart, A.L., Mills, K.M., Sepsis, P.G., King, A.C., McLellan, B.Y., Roitz, K., \& Ritter, P.L. (1997). Evaluation of CHAMPS, a physical activity promotion program for older adults. Annals of Behavioral Medicine, 19(4), 353-361. doi:10.1007/BF02895154

Stewart, A.L., Verboncoeur, C.J., McLellan, B.Y., Gillis, D.E., Rush, S., Mills, K.M., . . Bortz, W.M., II. (2001). Physical activity outcomes of CHAMPS II: A physical activity promotion program for older adults. The Journals of Gerontology. Series A, Biological Sciences and Medical Sciences, 56(8), M465-M470. doi:10.1093/gerona/56. 8.M465

Thabane, L., Ma, J., Chu, R., Cheng, J., Ismaila, A., Rios, L.P., . . . Goldsmith, C.H. (2010). A tutorial on pilot studies: The what, why and how. BMC Medical Research Methodology, 10, 1. PubMed ID: 20053272 doi:10.1186/1471-2288-10-1

Tremblay, M.S., Warburton, D.E.R., Janssen, I., Paterson, D.H., Latimer, A.E., Rhodes, R.E., . . . Duggan, M. (2011). New Canadian physical activity guidelines. Applied Physiology, Nutrition, and Metabolism, 36(1), 36-46. doi:10.1139/H11-009

Troiano, R.P., Berrigan, D., Dodd, K.W., Masse, L.C., Tilert, T., \& McDowell, M. (2008). Physical activity in the United States measured by accelerometer. Medicine \& Science in Sports \& Exercise, 40(1), 181-188. doi:10.1249/mss.0b013e31815a51b3

van Heeswijck, T., Paquet, C., Kestens, Y., Thierry, B., Morency, C., \& Daniel, M. (2015). Differences in associations between active transportation and built environmental exposures when expressed using different components of individual activity spaces. Health \& Place, 
33, 195-202. PubMed ID: 25862996 doi:10.1016/j.healthplace.2015. 03.003

Visser, M., Goodpaster, B.H., Kritchevsky, S.B., Newman, A.B., Nevitt, M., Rubin, S.M., . . . Harris, T.B. (2005). Muscle mass, muscle strength, and muscle fat infiltration as predictors of incident mobility limitations in well-functioning older persons. Journals of Gerontology. Series A, Biological Sciences and Medical Sciences, 60(3), 324-333. doi:10.1093/gerona/60.3.324

Wandersman, A., Duffy, J., Flaspohler, P., Noonan, R., Lubell, K., Stillman, L., . . . Saul, J. (2008). Bridging the gap between prevention research and practice: The interactive systems framework for dissemination and implementation. American Journal of Community Psychology, 41(3-4), 171-181. doi:10.1007/s10464-0089174-Z

Warburton, D.E.R., Jamnik, V.K., Bredin, N., \& Gledhill, N.; on behalf of the PAR-Q+ Collaboration. (2011). The Physical Activity Readiness Questionnaire for Everyone (PAR-Q+) and Electronic Physical Activity Readiness Medical Examination (ePARmed-X+). Health \& Fitness Journal of Canada, 4(2), 3-23.
Webber, S.C., Porter, M.M., \& Menec, V.H. (2010). Mobility in older adults: A comprehensive framework. The Gerontologist, 50(4), 443-450. PubMed ID: 20145017 doi:10.1093/geront/gnq013

Whitehead, A.L., Julious, S.A., Cooper, C.L., \& Campbell, M.J. (2016). Estimating the sample size for a pilot randomised trial to minimise the overall trial sample size for the external pilot and main trial for a continuous outcome variable. Statistical Methods in Medical Research, 25(3), 1057-1073. PubMed ID: 26092476 doi:10.1177/ 0962280215588241

World Health Organization. (2009). Global health risks: Mortality and burden of disease attributable to selected major risks. Geneva, Switzerland: Author.

Yamey, G. (2011). Scaling up global health interventions: A proposed framework for success. PLoS Medicine, 8(6), e1001049. doi:10.1371/ journal.pmed.1001049

Yardley, L., Beyer, N., Hauer, K., Kempen, G., Piot-Ziegler, C., \& Todd, C. (2005). Development and initial validation of the Falls Efficacy Scale-International (FES-I). Age and Ageing, 34(6), 614-619. PubMed ID: 16267188 doi:10.1093/ageing/afi196 